\title{
Uncertainty and its Impact on the Quality of Measurement
}

\author{
${ }^{1}$ Adel Elahdi M. Yahya and ${ }^{2}$ Martin Halaj \\ ${ }^{1}$ Faculty of Mechanical Engineering, Slovak University of Technology in Bratislava, Slovakia \\ ${ }^{2}$ Slovak Institute of Metrology, Section of Research and Quality Management, Slovakia
}

Received 2012-05-14; Revised 2012-06-22; Accepted 2012-06-22

\begin{abstract}
The imposition of practice, the current world, the laboratory measurement, calibration should be approved by points of credit to national or international and should be compatible with the requirements specification (ISO 17025) for the adoption of efficient laboratories. Those requirements were included the testing process or scale limits to doubt that mentioned in the measurement certificate, which recognizes the customer to achieve quality and efficiency in the process of measurement. In this study we would theoretically try to clarify, indicate what the uncertainty in the measurement, standard types of uncertainty and how to calculate the budget of uncertainty as we should show some examples of how the scientific calculation of the budget challenge with some measure the lengths of the laboratory. After analyzing the results we had found during the measurement using CMM, we had found that the value of non-statistical uncertainty in the measurement type (b) piece length of one meter was $\pm 1.9257 \mu \mathrm{m}$. and when using the configuration measuring device, we had gotten the value of the extended standard combined uncertainty $\pm 2.030 \mu \mathrm{m}$ when measured the screws value of $1.2707 \mathrm{~mm}$. When used the configuration measuring device, we had gotten the value of the extended standard combined uncertainty $\pm 2.030 \mu \mathrm{m}$ when measuring the screws value of $1.2707 \mathrm{~mm}$. We concluded that the impact of uncertainty on the measured results a high fineness degree and less impact on the smoothness of a piece with low fineness, careful calibration of measuring instrument Careful calibration of measuring instrument and equipment by measurement standard is of the utmost importance and equipment by measurement standard is of the utmost importance and laboratories must calculate the uncertainty budget as a part of measurement evaluation to provide high quality measurement results.
\end{abstract}

Keywords: Coordinate Measuring Machine (CMM), Measurement Certificate, Important Concepts, Good Quality Measurements, Industrial Standardization, Required Accuracy

\section{INTRODUCTION}

The exchange of goods between the countries of the world requires a uniform measurement of manufacturing products agreed variations are almost non-existent in most of the work and to achieve the required accuracy of measurements based on the need to use the tools and measuring instruments accurate or at a high level of accuracy, this depend on the method of preservation, handling and calibration for the production of these products. The measurement process is the act of assigning a value to some physical variable, by operating sensors and instruments in conjunction with data acquisition and reduction procedures. In an ideal measurement, the value assigned by the measurement would be the actual value of the physical variable intended to be measured.
However, measurement process and environmental errors bring in uncertainty in the correctness of the value resulting from the measurement. To give some measure of confidence to the measured value, measurement errors must be identified and their probable effect on the result estimated. Uncertainty is simply an interval estimate of a possible set of values for the error in the reported results of a measurement. The process of systematically quantifying error estimates is known as uncertainty analysis (Bertrand-Krajewski, 2011).

Measuring the dimensions of science and art is related to measure and adjust the lengths and dimensions and accuracy measurement is a strong edifice upon which the modern industry and the basis upon which all production stages. The concepts of measurement errors, uncertainty in measurement, calibration of measuring devices, belong 
among the most important concepts upon which the standardization of scientific and industrial standardization.

Along with this philosophy, rigorous application or integration of uncertainty assessment methodology is an integral part of all monitoring phases. The most important benefits of standardized uncertainty analysis implementation are: identification of the dominant sources of error, their effects on the result and estimation of the associated uncertainties, facilitation of meaningful and efficient communication of data quality, facilitation of selecting the most appropriate and cost effective measurement devices and procedures for a given measurement, consideration and reduction of the risks in decision making and evidence of compliance with regulations (ISO/IEC Guide 98-3, 2008).

\section{MATERIALS AND METHODS}

\subsection{Measurement Errors and Measurement Uncertainties}

It is important not to confuse the terms 'error' and 'uncertainty' (Fig. 1). On one hand, error is the difference between the measured value and the 'true value' of the measurand, while the uncertainty can be shortly described as a quantification of the doubt about the measurement result (Kurekova et al., 2005).

When designing and performing measurement, one has to consider following effects and restrictions affecting the obtained measurement result:

- The measuring instrument can suffer from errors including bias, changes due to aging, wear, or other kinds of drift, poor readability, noise (for electrical instruments) and many other problems

- The item being measured (measurand) may not be stable (imagine trying to measure the size of an ice cube in a warm room)

- Imported uncertainties can occur-calibration of your instrument has an uncertainty which is then built into the uncertainty of the measurements you make. On the other hand, the uncertainty due to not calibrating would be much worse

- Operator skill is very important, as some measurements depend on the skill and judgement of the operator. One person may be better than another at the delicate work of setting up a measurement, or at reading fine detail by eye

- Sampling issues represent the fact that the measurements you make must be properly representative of the process you are trying to assess

- The environment affects the measurement in different ways, e.g., temperature, air pressure, humidity and many other operational conditions can affect the measuring instrument or the item being measured (Bell, 2001)

\subsection{Uncertainty of Measurement is Important}

You may be interested in uncertainty of measurement simply because you wish to make good quality measurements and to understand the results. However, there are other more particular reasons for thinking about measurement uncertainty (Bell, 2001):

- Calibration: the uncertainty of measurement must be reported on the certificate

- Testing: the uncertainty of measurement can affect the decision to pass or fail result

- Tolerancing: you need to know the uncertainty before you can decide whether the tolerance is met

\subsection{Ways to Estimate Uncertainties}

There are two approaches to estimate the uncertainty-'Type A' and 'Type B' methods. Uncertainty evaluations of both types are needed in most measurement situations. Anyway, the overall uncertainty budget covers all uncertainty sources, regardless the method used for their evaluation:

\subsection{Type A Evaluation (uA)}

Uncertainty estimates using statistics (usually from repeated readings).

\subsection{Type B Evaluations (uB)}

Uncertainty estimates obtained from other information sources. This could be information from past experience of the measurements, from calibration certificates, manufacturer's specifications, from calculations, from published information and from common sense.

\subsection{Combined Standard Uncertainty}

After calculating the standard uncertainties for all the sources of uncertainty in your measurement then the total uncertainty in the measurement, called the combined standard uncertainty, is given by the square root of the sum of the squares of all the uncertainties in the measurement (Buffler et al., 2009).

Quantity defining an interval about the result of a measurement that may be expected to encompass a large fraction of the distribution of values that could reasonably be attributed to the measurand.

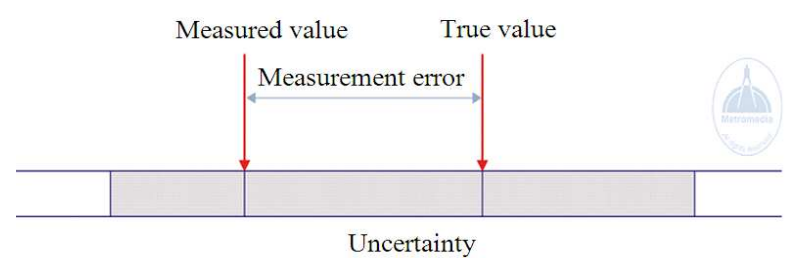

Fig. 1. Measurement uncertainty, measurement error (Kurekova et al., 2005) 


\subsection{Expanded Uncertainty 2.8. Coverage Factor}

Numerical factor used as a multiplier of the combined standard uncertainty in order to obtain an expanded uncertainty (SASO, 2006).

\subsection{Calcuation of the uncertainty budget}

When one intends to calculate the uncertainty budget, the uncertainty sources in the measurement must be identified and evaluated first. All those sources must be identified and collected in a summary of these values to calculate the uncertainty as described schedules and so-called uncertainty budget. We will calculate of the budget uncertainty for some instruments measure dimensions, including Coordinate Measuring Machine (CMM), roundness measuring machine, measuring the machine roughness of surfaces and tracking device figure-type Contracer.

After the preparation of the uncertainty budget, the standard combined uncertainty is calculated $\left(\mathrm{u}_{\mathrm{C}}\right)$ shown in Eq. 1 that composed of two types:

$$
\mathrm{u}_{\mathrm{C}}=\sqrt{\mathrm{u}_{\mathrm{A}}^{2}+\mathrm{u}_{\mathrm{B}}^{2}}
$$

$\mathrm{K}=1$, where $\mathrm{K}$ is coverage factor

Type $A: U_{A}$ is given by Eq. 2:

$\mathrm{U}_{\mathrm{A}}=\frac{\mathrm{s}}{\sqrt{\mathrm{n}}} \mathrm{K}_{\mathrm{A}}$

Where:

$\mathrm{s} \quad=$ Standard deviation

$\mathrm{n} \quad=$ Number of measurement

$\mathrm{KA}=$ Student distribution coefficient

Type B: $\mathrm{U}_{\mathrm{B}}$ is given by Eq. 3:

$\mathrm{U}_{\mathrm{B}}^{2}=\mathrm{U}_{\mathrm{BE}}^{2}+\mathrm{U}_{\mathrm{BM}}^{2}+\mathrm{U}_{\mathrm{BT}}^{2}+\ldots \ldots .$.

Where:

$\mathrm{U}_{\mathrm{BE}}=$ Standard uncertainty. Uncertainty as a result of the accuracy of the machine and we get a booklet Specifications

$\mathrm{U}_{\mathrm{MB}}=$ Measuring instrument uncertainty. We get from the calibration certificate for the device, computed from the limits of error $( \pm a)$ and taken from the manufacturer directory is usually equal to $\mathrm{a} / 3$ at $\mathrm{K}=1$

$\mathrm{U}_{\mathrm{BT}}=$ Uncertainty due to temperature changes. It consists of two parts

A. Uncertainty as a result of expansion coefficient is calculated from the errors resulting from the different coefficients of thermal expansion of a measuring instrument and the measured object. Due to temperature differences between the manufactured part and the measuring device, shown in Eq. 4:

$$
\mathrm{LU}_{\alpha}\left(\mathrm{t}_{\mathrm{s}}-\mathrm{t}_{\mathrm{p}}\right)
$$

B. Uncertainty result of differences in actual temperature of the laboratory and the standard temperature $20^{\circ} \mathrm{C}$ that is usually considered ad a standard temperature measurement in laboratories, shown in Eq. 5:

$\mathrm{L} \alpha \mathrm{U}_{\Delta \mathrm{t}}$

Where:

$\mathrm{U}_{\mathrm{a}}=$ Uncertainty as a result of thermal expansion coefficient

$\mathrm{U}_{\Delta \mathrm{t}}=$ Uncertainty as a result of the change in surrounding temperature

$\mathrm{L}=$ Length of the piece measured

$\mathrm{t}_{\mathrm{s}} \quad=$ Temperature of the scale

$\mathrm{t}_{\mathrm{p}} \quad=$ Temperature of the measured object

a $=$ Coefficient of thermal expansion

To increase the level of confidence in the results to the $95 \%$, calculated to extend standard uncertainty is obtained when the coverage factor $\mathrm{K}=2$. Expanded standard combined, given by Eq. 6 :

Uncertainty $(\mathrm{U})=\sqrt{\mathrm{U}_{\mathrm{A}}^{2}+\mathrm{U}_{\mathrm{B}}^{2}}$, at $\mathrm{K}=2$

After calculating expanded standard combined uncertainty is added to the average measured results to obtain:

The final result of a comprehensive measurement uncertainty $\mathrm{X} \pm \mathrm{U}$

where:

$\mathrm{X}=$ Estimate of the measurement result, usually the average mean of repeated measurements

$\mathrm{U}=$ Expanded standard combined uncertainty at the degree of confirmation $95 \%$ and $\mathrm{K}=2$.

\section{RESULTS}

\subsection{Practical Application for the Calculation of the Budget Uncertainty with Some Instrumentation Measure Dimensional}

From the importance of account uncertainty in measurement laboratories and testing, we have with a dedicated team of engineers, technicians laboratory measure-dimensional status of technical mechanical Tripoli. 
Table 1. Uncertainty Budget for CMM-type SIP (UE, 2005)

\begin{tabular}{lc}
\hline Uncertainty source & Value \\
\hline Uncertainty CMM (from Specification) & $\mathrm{U}_{\mathrm{BE}}=\frac{0.3+0.4 \mathrm{~L}}{3}=0.1+0.13 \mathrm{~L}$ \\
Uncertainty index measurement (from Specification) & $\mathrm{U}_{\mathrm{BK}}=\frac{0.3}{3}=0.1$ \\
Uncertainty gauge block & $\mathrm{U}_{\mathrm{BM}}=\frac{0.1}{3}=0.03$ \\
Coefficient of thermal expansion of the piece & $\mathrm{a}=11.5 \pm 1$ \\
Coefficient of thermal expansion of the scale & $\mathrm{a}=11.5 \pm 2$ \\
Uncertainty as a result of thermal expansion coefficient & $\mathrm{U}_{\alpha}=\frac{+2-(-2)}{\sqrt{3}}=2.3$ \\
Temperature difference between the piece and the scale & $\mathrm{t}_{\mathrm{s}}-\mathrm{t}_{\mathrm{E}}=0.2$ \\
Uncertainty as a result of different temperature lab & $\mathrm{U}_{\Delta \mathrm{t}}=\frac{0.2}{\sqrt{3}}=0.115$ \\
\hline
\end{tabular}

Table 2. Uncertainty budget for roundness measurement device- roundness tester (Mitutoyo. Certificate of calibration Round tester instrument; Mitutoyo. Specification Sheet of Form tracer instrument)

\begin{tabular}{|c|c|}
\hline Uncertainty source & Value \\
\hline $\mathrm{U}_{\mathrm{A}}$ & $\mathrm{U}_{\mathrm{A}}=\frac{\mathrm{s}}{\sqrt{\mathrm{n}}} \times \mathrm{K}_{\mathrm{a}}=\frac{0.07070}{\sqrt{5}} \times 1.4=0.044 \mu \mathrm{m}$ \\
\hline $\mathrm{U}_{\mathrm{BE}}$ & $\begin{array}{l}\mathrm{U}_{\mathrm{BK}}=\frac{0.7+6 \mathrm{H} / 1000}{3}=\frac{0.7+0.006 \mathrm{H}}{3}=\frac{0.91684}{3}=0.3056 \mu \mathrm{m} \\
\text { Where } \mathrm{H}=36.14 \mathrm{~mm}\end{array}$ \\
\hline $\mathrm{U}_{\mathrm{BM}}$ & $\begin{array}{l}\text { Where } H=36.14 \mathrm{~mm} \\
\mathrm{U} \text { of measurement for detector displacement } 0.09 \mu \mathrm{m} \text { at } \mathrm{K}=2.01 \\
\mathrm{U} \text { of measurement for relative error of measured magnification } 0.22 \mu \mathrm{m} \text { at } \mathrm{K}=2.01 \\
\mathrm{U} \text { of measurement for rotational accuracy in radius direction } 0.08 \mu \mathrm{m} \text { at } \mathrm{K}=1.96 \\
\frac{0.09}{2.01}+\frac{0.22}{2.01}+\frac{0.08}{1.96}=0.193 \mu \mathrm{m}\end{array}$ \\
\hline $\mathrm{U}_{\mathrm{BT}}$ & $\mathrm{U}$ of temperature change in lab $\pm 0.2^{\circ} \mathrm{C} \quad \mathrm{U}_{\Delta \mathrm{t}}=\frac{0.2}{\sqrt{3}}=0.115$ \\
\hline
\end{tabular}

Table 3. Uncertainty budget for a device to measure roughness of surfaces-type Surftest (Mitutoyo. Specification Sheet of Form tracer instrument; Mitutoyo. Certificate of calibration Surftest instrument)

\begin{tabular}{|c|c|}
\hline Uncertainty Source & Value \\
\hline $\mathrm{U}_{\mathrm{A}}$ & $\mathrm{U}_{\mathrm{A}}=\frac{\mathrm{s}}{\sqrt{\mathrm{n}}} \times \mathrm{K}_{\mathrm{a}}=\frac{0.00139}{\sqrt{10}} \times 1=4.395 \times 10^{-4} \mu \mathrm{m}$ \\
\hline \multirow[t]{2}{*}{$\mathrm{U}_{\mathrm{BM}}$} & $\begin{array}{l}U \text { of straightness of drive unit } 0.23 \mu \mathrm{m} \text { at } K=2.01 \\
U \text { of relative error of horizontal magnification } 1.18 \mu \mathrm{m} \text { at } K=3.18 \\
U \text { surface step measurement } 0.13 \mu \mathrm{m} \text { at } K=1.96 \\
U \text { of repeatability of Ra } 0.19 \mu \mathrm{m} \text { at } K=1.96 \\
U \text { of radius of stylus measurement } 0.12 \mu \mathrm{m} \text { at } K=1.96\end{array}$ \\
\hline & $\mathrm{U}_{\mathrm{BM}}=\frac{0.23}{2.01}+\frac{1.18}{3.18}+\frac{0.13}{1.96}+\frac{0.19}{1.96}+\frac{0.12}{1.96}=0.7098 \mu \mathrm{m}$ \\
\hline $\mathrm{U}_{\mathrm{BT}}$ & $\mathrm{U}$ of temperature change in lab $\pm 0.2^{\circ} \mathrm{C} \quad \mathrm{U}_{\Delta \mathrm{t}}=\frac{0.2}{\sqrt{3}}=0.115$ \\
\hline
\end{tabular}

The application of a practical calculation of the budget uncertainty for some instruments measure dimensions, including Coordinate Measuring Machine (CMM), are provided in Table 1, roundness measuring machine, are provided in Table 2, measuring the machine roughness of surfaces, are provided in Table $\mathbf{3}$ and tracking device figuretype Contracer, are provided in Table 4.

It is explained tables as follows:

- In (Table 1) Uncertainty Budget for CMM of type B is $\mathrm{U}_{\mathrm{B}}=0.46+3.825 \mathrm{~L}(\mu \mathrm{m} ; \mathrm{m})$ for $\mathrm{K}=2$ and $\mathrm{L}$ is the measuring length in $\mathrm{m}$. In this way the amount of uncertainty of type B when measuring the length of a piece of 1 meter in length is $\pm 1.9257 \mu \mathrm{m}$

- In (Table 2) Uncertainty Budget for roundness measurement device, The final result of measurement equal $(\mathrm{X} \pm \mathrm{U})=1.1 \pm 0.318(\mu \mathrm{m} ; \mu \mathrm{m})$

- In (Table 3) Uncertainty Budget for a device to measure roughness of surfaces, The final result of measurement equal $(\mathrm{X} \pm \mathrm{U})=1.4338 \pm 0.7191 \mu \mathrm{m}$

- The final result of measurement from (Table 4) for tracking device figure: measured value \pm the amount of uncertainty, The final result of measurement: $X \pm$ $\mathrm{U}=1.2707 \pm 2.030 \mu \mathrm{m}$ 
Table 4. Uncertainty budget for tracking device figure-type Contracer (Mitutoyo SV_C500) (Mitutoyo. Specification Sheet of Form tracer instrument, Mitutoyo. Certificate of calibration Surftest instrument)

\begin{tabular}{|c|c|}
\hline Uncertainty Source & Value \\
\hline $\mathrm{U}_{\mathrm{A}}$ & $\mathrm{U}_{\mathrm{A}}=\frac{\mathrm{s}}{\sqrt{\mathrm{n}}} \times \mathrm{K}_{\mathrm{a}}=\frac{0.000539}{\sqrt{6}} \times 1.3=0.000286 \mu \mathrm{m}$ \\
\hline $\mathrm{U}_{\mathrm{BE}}$ & $\begin{array}{l}U b_{\mathrm{ex}}=1+2 \mathrm{~L} / 100=1+2 \times 20 / 100=1.4 \mu \mathrm{m} \\
U b_{\mathrm{ez}}=4+12 Z \times 1 / 25=4+12 \times 0.8264 \times 0.04=4.3966 \mu \mathrm{m} \\
U b_{\mathrm{e}}=1.4+4.3966=5.3966 / 3=1.9322 \mu \mathrm{m} \\
\text { Where: } \mathrm{L}=20 \mathrm{~mm} \text { and } Z=0.8264 \mathrm{~mm}\end{array}$ \\
\hline $\mathrm{U}_{\mathrm{BM}}$ & $\begin{array}{l}U \text { of straightness of drive unit measurement } 0.21 \mu \mathrm{m} \text { at } \mathrm{K}=2.01 \\
U \text { of } \mathrm{X} \text {-axis measures accuracy } 1.06 \mu \mathrm{m} \text { at } \mathrm{K}=2.01 \\
U \text { of } Z \text {-axis measuring accuracy } 1.30 \mu \mathrm{m} \text { at } \mathrm{K}=4.3 \\
\mathrm{U}_{\mathrm{BM}}=\frac{0.21}{2.01}+\frac{1.06}{3.01}+\frac{1.30}{4.3}=0.934 \mu \mathrm{m}\end{array}$ \\
\hline $\mathrm{U}_{\mathrm{MT}}$ & $U$ of temperature change in $l a b \pm 0.2^{\circ} \mathrm{C} \quad \mathrm{U}_{\Delta \mathrm{t}}=\frac{0.2}{\sqrt{3}}=0.115$ \\
\hline
\end{tabular}

\section{DISCUSSION}

- During the measurement using CMM, we found that the value of non-statistical uncertainty in the measurement type (b) piece length of one meter is $\pm 1.9257 \mu \mathrm{m}$

- We found that the value of the extended standard combined uncertainty $\pm 0.318 \mu \mathrm{m}$ during measuring piece is equal to $1.1 \mu \mathrm{m}$ when measured by the measurement of roundness device.

- The value of the extended standard combined uncertainty $\pm 0.7191 \mu \mathrm{m}$ when measuring piece with a value for the roughness is equal to $1.4338 \mu \mathrm{m}$ with using roughness measuring machine.

- When using the configuration measuring device, we got the value of the extended standard combined uncertainty $\pm 2.030 \mu \mathrm{m}$ when measuring the screws value of $1.2707 \mathrm{~mm}$

\section{CONCLUSION}

When analyzing the result, several conclusions were observed:

- When considering measurements by a coordinate measuring machine, the uncertainty value has a significant impact on the measurement result when measuring the dimensions of small jobs and has a smaller effect when measuring large dimensions

- When using the roundness device, the uncertainty has a high effect on the measuring result

- We found that the impact of uncertainty on the measured results a high fineness degree and less impact on the smoothness of a piece with low fineness

- When using the configuration measuring device, we found that the value of uncertainty impact on the measurement results for small dimensions
- Laboratories must calculate the uncertainty budget as a part of measurement evaluation to provide high quality measurement results

- Careful calibration of measuring instruments and equipment by measurement standard is of the utmost importance

- The traceability chain to ensure the device measurement reference must be implemented

- Attention to training specialists and technicians to be able $t$ analyses uncertainty effects must be executed

\section{REFERENCES}

Bertrand-Krajewski, J.L., 2011. Evaluation of Uncertainties in Measurements.

Bell, S., 2001. Measurement good practice guide: A beginner's guide to uncertainty of measurement. 1st Edn., National Physical Laboratory, Teddington, Middlesex, United Kingdom.

Kurekova, E., P. Gabko and M. Halaj, 2005. Measurement in Technology. A Textbook from the Multimedia Courseware Metromedia-Online. Peter Juriga-rafické štúdio, Bratislava, ISBN-10: 8089112056 pp: 723.

Buffler, A., A. Saalih, L. Fred and C. Bob, 2009. Introduction to measurement in the physics laboratory: A probabilistic approach. University of Cape Town.

SASO, 2006. Guide to the Expression of Uncertainty in Measurement. Saudi Arabian Standards Organization.

ISO/IEC Guide 98-3, 2008 Guide to the Expression of Uncertainty in Measurement (Geneva, Switzerland: International Organization for Standardization). ISO/IEC.

UE, 2005. Czech Metrological Institute, Laboratory of Fundamental Metrology. Uncertainty Evaluation. 